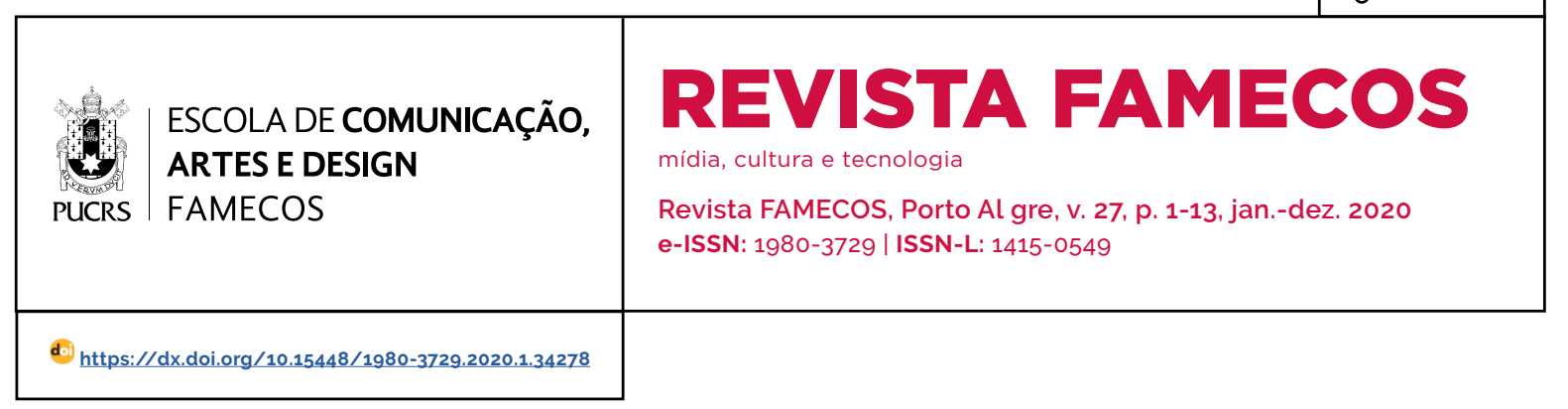

JORNALISMO

\title{
O uso crítico da memória nas narrativas jornalísticas sobre o rompimento da barragem da Vale
}

\author{
The critical use of memory in the journalistic narratives about the rupture of the Vale dam \\ El uso crítico de la memoria en las narrativas periodísticas sobre el rompimiento de la \\ presa de Vale
}

\author{
Marta Regina Maia ${ }^{1}$ \\ orcid.org/0000-0002-0580-2147 \\ martamaia@ufop.edu.br
}

Recebido em: 27 mai. 2019.

Aprovado em: 22 nov. 2019. Publicado em: 16 jul. 2020.

\section{(c) (1)}

Artigo está licenciado sob forma de uma licença Creative Commons Atribuição 4.0 Internacional.
RESUMO: Averiguar o uso crítico da memória na cobertura jornalistica de situações impactantes é o objetivo deste artigo, que tem como proposta a reflexão sobre dois acontecimentos próximos que ocorreram no estado de Minas Gerais no século XXI. O propósito é analisar a cobertura dos jornais Folha de S. Paulo, $O$ Estado de S. Paulo e O Globo sobre o rompimento da barragem da Vale, em 2019. em Brumadinho, e sua relação com o rompimento da barragem da Samarco, em 2015, em Mariana, por intermédio de uma análise de conteúdo, que apresenta como eixos operadores os "portadores de memória" identificados como "Fenômenos" e "Sujeitos". Este olhar está ancorado nos conceitos de acontecimento e memória, em associação com o papel testemunhal do jornalismo. Nota-se que a cobertura proporcionou um relativo destaque para a conexão entre os dois acontecimentos recorrendo ao uso crítico da memória.

Palavras-Chave: Narrativas. Memória. Cobertura jornalistica

ABSTRACT: To ascertain the critical use of memory in journalistic coverage of shocking situations is the aim of this article, which has as its proposal the reflection on two events occurred in the state of Minas Gerais in the 21st century. The purpose is to analyze the coverage of the Folha de S. Paulo, O Estado de S. Paulo and O Globo newspapers on the rupture of the Vale dam in Brumadinho in 2019, and its relation to the rupture of the Samarco dam in 2015 in Mariana through a content analysis, which presents as the operative axes the "memory bearers" identified as "Phenomena" and "Subjects", anchored in the concepts of happening and memory, in association with the journalism's witness role. It is noted that the coverage provided a relative highlight to the connection between the two happenings using the critical use of memory.

Keywords: Narratives. Memory. Journalistic coverage.

RESUMEM: Averiguar el uso crítico de la memoria en la cobertura periodistica de situaciones impactantes es el objetivo de este artículo, que tiene como propuesta la reflexión sobre dos acontecimientos próximos que ocurrieron en el estado de Minas Gerais en el siglo XXI. El propósito es analizar la cobertura de los periódicos Folha de S. Paulo, O Estado de S. Paulo y O Globo sobre el rompimiento de la represa de la Vale en 2019, en Brumadinho, y su relación con el rompimiento de la represa de Samarco en 2015, Mariana, por intermedio de un análisis de contenido, que presenta como ejes operadores a los "portadores de memoria" identificados como "Fenómenos" y "Sujetos" anclados en los conceptos de acontecimiento y memoria, en asociación con el papel testimonial del periodismo. Se observa que la cobertura proporcionó un relativo destaque para la conexión entre los dos acontecimientos recurriendo al uso crítico de la memoria. Palabras clave: Narrativas. Memoria. Cobertura periodística. 


\section{Introdução}

Qual o papel da cobertura jornalística e do uso crítico da memória em situações extremas como o rompimento de barragens que ocasionam sérios problemas ambientais e sociais? Para além disso, é possivel questionar: quando a memória é acionada e qual o seu lugar, tanto individual quanto coletivamente, relacionada a esse tipo de acontecimento? A partir dessas questões, tem-se como proposta a reflexão sobre dois acontecimentos próximos que ocorreram no estado de Minas Gerais no século XXI. O objetivo é analisar a cobertura do rompimento da barragem da barragem da Vale, em 2019, em Brumadinho, e sua relação com o rompimento da barragem da Samarco, em 2015, em Mariana. ${ }^{2}$

O rompimento da barragem em 2019 ocorreu logo após uma notícia que, na época, não recebeu muita atenção por parte dos meios de comunicação. Em dezembro de 2018 a licença de ampliação do complexo das Minas Feijão e Jangada (localizadas na região de Brumadinho) foi aprovada pela Câmara de Atividades Minerárias (CMI) do Conselho Estadual de Politica Ambiental, o que significou a revisão da classificação do impacto do empreendimento, situando-o em um nivel menos perigoso e desconsiderando os impactos em possiveis problemas de captação de água (o Rio Paraopeba era um dos fornecedores de água para a região metropolitana de Belo Horizonte), além de outras questões conflituosas.

Em 2019, quando outro acontecimento irrompe de maneira igualmente trágica, a força que adquire é bem maior visto que a reverberação ganha um desdobramento que amplifica o acontecimento anterior. É possivel verificar que a cobertura jornalística caminha em direção às causas e não mais somente às consequências. Percebe-se que as matérias definidas como corpus desse artigo buscam trazer à tona os depoimentos dos atingidos pelo rompimento em 2015 no sentido de refletir sobre os desdobramentos que um desastre ${ }^{3}$ como esse pode ocasionar. Além disso, as áreas desocupadas em Minas Gerais, que envolvem sete represas da Vale, já atingiram cinco cidades e mais de mil pessoas já foram retiradas de suas casas. O principal acesso de Belo Horizonte (BH) a Ouro Preto chegou a ser interditado, e diversas matérias apontam outros lugares em situação de risco. Pode-se dizer que o acontecimento "Brumadinho" ganhou uma amplitude por conta do acontecimento anterior que ainda reverbera de maneira intensa justamente por trazer em seus desdobramentos rastros de injustiça e iniquidade e ainda potencializa novos horizontes por conta dos infortúnios ocasionados. Um dado que merece ser mencionado é que no caso de Mariana não havia sirenes, o que poderia ter evitado algumas mortes; já no caso de Brumadinho havia sirenes que foram imediatamente tragadas pela lama. Ou seja, as empresas não tiveram uma atuação preventiva, o que gera uma sensação de iniquidade.

Nessa perspectiva, propõe-se uma discussão sobre a cobertura jornalística do acontecimento de 2019 a partir da relação que se estabelece entre os dois desastres, compreendendo o jornalismo como um espaço de produção de sentidos no interior da sociedade ${ }^{4}$. Para isso, achamos necessária, inicialmente, uma reflexão sobre memória, jornalismo e acontecimento para então investigarmos como a cobertura estabelece associações entre os dois e se afasta de narrativas do presente para dar lugar a outras temporalidades em que o passado e o futuro ocupam espaços relevantes nas produções.

Avalia-se que a proximidade do acontecimento não facilita uma metodologia de análise mais estendida, então, nesse sentido, propõe-

\footnotetext{
2 Em 5 de novembro de 2015, ocorreu o rompimento da barragem do Fundão, da mineradora Samarco, controlada pela Vale e pela BHP Billiton, no municipio de Mariana, em Minas Gerais. Morreram 19 pessoas, além da destruição de vários distritos e do Rio Doce. No dia 25 de janeiro de 2019, houve o rompimento da Mina Córrego do Feijão, da mineradora Vale, na região de Brumadinho, Minas Gerais, ocasionando a destruição do entorno e do Rio Paraopeba. Até novembro de 2019, o número de pessoas mortas era de 252, além de 18 pessoas desaparecidas.

3 Serão utilizadas as palavras "desastre" e/ou "crime" como referência ao ocorrido. Desastre, por conta dos desdobramentos que se sucederam ao rompimento da barragem. Crime, visto que, embora as investigações ainda não tenham sido concluidas, no âmbito da Justiça estadual a Vale já foi condenada.

4 Essa análise faz parte de um projeto de pesquisa mais amplo de averiguação sobre o caráter crítico da cobertura jornalistica contemporânea.
} 
se a análise de conteúdo, tendo como eixos operadores alguns elementos memoriais, que serão explicitados no item de análise, como referências procedimentais para essa investigação. O recorte será a chamada imprensa hegemônica ou de referência justamente para a verificação do modus operandi desses veículos, muitas vezes acusados pela realização de coberturas voltadas somente para o presente, frágeis e descontextualizadas. Serão avaliados 15 dias de cobertura dos jornais Folha de S. Paulo, 0 Globo e Estado de S. Paulo, considerados os três maiores jornais de informação do Brasil. ${ }^{5}$

\section{Memória, jornalismo e acontecimento}

O acompanhamento de uma cobertura jornalistica suscita discussões sobre acontecimento, experiência, temporalidades e, mais ainda, reflexões relacionadas a memória do tempo social. Como o jornalismo trabalha com acontecimentos e com a presença dos sujeitos no tempo, tem-se que esse tempo é sempre humano e requer uma dimensão narrativa para a produção de sentidos.

Essa discussão pode ser iniciada com o acompanhamento de algumas questões que o historiador Reinhart Koselleck (2006) apresenta e que contribuem para a reflexão sobre a semântica dos tempos históricos ao indicar o "espaço de experiência" e o "horizonte de expectativa" como categorias que propulsionam os possiveis da história a partir da experiência dos sujeitos e pelas expectativas que eles acionam nas vivências cotidianas.

Para o autor, e isso interessa particularmente ao tema desse trabalho, a experiência é uma categoria que pertence ao passado e que se realiza no presente por intermédio dos vestígios, das permanências e das fontes; ela "é o passado atual, aquele no qual acontecimentos foram incorporados e podem ser lembrados" (KOSELLECK, 2006, p. 309). Ainda para ele, a experiência comporta a elaboração racional, mas também movimentos inconscientes de outros sujeitos, o que leva a questão da presença do social na experiência individual.

O "horizonte de expectativa", voltado para o futuro - e que comporta medos, incertezas e projetos -, embora contemple tanto a dimensão racional quanto a especulativa, mantém diferença com a experiência na medida em que não pode ser repetida ou confirmada, afinal "as expectativas podem ser revistas, as experiências feitas são recolhidas" (KOSELLECK, 2006, p. 311). Koselleck argumenta ainda que tanto a "expectativa" quanto a "experiência" se realizam no presente, no hoje.

Mesmo sendo duas categorias de análise. elas "não se opõem uma à outra, como em uma dicotomia qualquer [...] São categorias complementares, visto que a experiência abre espaços para um certo horizonte de expectativas". (BARROS, 2013, p. 141). Ao trazer essas categorias para a esfera hermenêutica, Reinhart Koselleck problematiza certas visadas que entendem as relações entre passado e futuro de maneira causal e até mesmo linear. A noção de progresso, por exemplo, se valeu de distintas experiências em todo o mundo com o objetivo de estabelecer modos de comparação entre civilizações que teriam ou não alcançado determinado patamar de desenvolvimento técnico/social. Ele deixa claro que "essa constatação, de uma transição quase perfeita das experiências passadas para as expectativas vindouras, não pode ser aplicada de igual maneira a todas as camadas sociais" (KOSELLECK, 2006, p. 315). Essa relação aprofundou suas diferenças e levou a uma assimetria entre experiência e expectativa, ainda segundo o autor, que foi ampliada pelo advento da modernidade.

Pode-se compreender, a partir de Koselleck, que a experiência (passado) do rompimento da barragem de Mariana não conseguiu alertar à sociedade sobre os desdobramentos de um acontecimento tão drástico. O "horizonte de expectativa" (futuro-presente) não conseguiu descortinar a possibilidade de novos desastres

Disponivel em: https://www.poder360.com.br/midia/tiragem-impressa-dos-maiores-jornais-perde-520-mil-exemplares-em-3-anos/. Acesso em: 20 abr. 2019. Para efeito comparativo, optou-se por não utilizar o primeiro jornal em vendagem (e terceiro, quando se consideram os assinantes digitais) por se tratar de jornal que opera em nível diferenciado de cobertura, mais voltado para matérias curtas e populares, que é o jornal Super Notícia, de MG. 
em lugares sabidamente comprometidos pela falta de segurança e garantia aos individuos e comunidades. De todo modo, o rompimento em 2019 problematiza, de maneira contundente, a existência de barragens que oferecem perigo iminente ao entorno, chamadas de barragens a montante 6 . A partir desse acontecimento, podese dizer que houve um tensionamento entre as duas instâncias, visto que o passado foi acionado, sob mediação do presente, no sentido de ser reavaliado a partir de expectativas do futuro. Foram efetuadas alterações nos procedimentos em outras regiões do país, o que não significa a resolução dos problemas, mas, ao menos, um agenciamento dos envolvidos no sentido da redução de danos.

Compreendendo que a memória só pode ser acionada pelo presente, é possivel complementar a discussão com algumas perspectivas apontadas pelo sociólogo Michael Pollak (1989) quando ele ressalta os tensionamentos ocasionados pelos conflitos do tempo presente no sentido de enquadrar determinadas versões sobre o passado. Essas memórias em disputa estão em constante reinterpretação de um passado que tem a lembrança e o esquecimento como elementos dialéticos de todo esse processo.

Ao discutir o aspecto seletivo da memória, Pollak (1989) indica a existência da memória oficial ou hegemônica e a memória subterrânea que estão em constante conflito, visto que grupos sociais, segundo o autor, aguardam um momento adequado para reinterpretarem o próprio passado. Ainda para ele, "os dominantes não podem jamais controlar perfeitamente até onde levarão as reivindicações que se formam ao mesmo tempo em que caem os tabus conservados pela memória oficial anterior" (POLLAK, 1989, p. 5). Nessa perspectiva é mister dizer que um novo acontecimento engendra um percurso narrativo que pode ter sido silenciado, marginalizado, mas não esquecido. Tanto que ele ressurge com uma força ainda maior na esteira de outra ocorrência de mesmo tipo.

Se o passado consegue ser acionado a partir desse outro acontecimento que mantém aproximações com o anterior é porque emerge o que Pierre Nora (1993) denomina de "lugares de memória", em sua tripla dimensão: material, funcional e simbólica. A primeira, como o nome diz, mantém relação com as condições materiais, manifestadas, da memória. O segundo, dá sustentação ao processo de propagação da memória, e o terceiro envolve o aspecto da representação desse passado.

Isso posto, é preciso pensar sobre o papel da memória coletiva nesse cenário em constante disputa, onde esses desastres se configuram como acontecimentos midiáticos narrativizados. Os meios de comunicação, como dispositivos sociais, narram essas histórias que movimentam o imaginário social e conformam memórias. Importante registrar que esses dispositivos não são meros aparatos técnicos que reproduzem fatos lisos, diretos, mas sim representam um "conjunto heterogêneo de materiais e de processos que não só 'decorre' da tecnologia, mas que, sobretudo, dá direção e sentido a seu uso" (BRAGA, 2011, p. 11).

$O$ acontecimento é assim configurado pela narrativa dos meios, afinal, como explica Louis Queré (2012), ele também é experimentado na própria configuração do discurso. Para ele, os acontecimentos são mudanças experimentadas em consonância com "as dimensões do afeto, do conhecimento e da prática" (QUERÉ, 2012, p. 37) e isso implica sua natureza relacional, como lembra Vera França (2012), que coaduna com a perspectiva adotada por Queré, ao dizer que os acontecimentos rompem com um estado de normalidade e com isso levantam sentidos que afetam os sujeitos e, o que interessa mais de perto nesse momento, "convocam um passado e re-posicionam o futuro" (FRANÇA, 2012, p. 14).

Antes de serem configurados discursivamente, os acontecimentos irrompem enquanto fenômenos, como argumenta Vera França ao dizer, na perspectiva de Louis Queré, que existe

\footnotetext{
6 No dia 18 de fevereiro, a Agência Nacional de Mineração (ANM) determinou a eliminação de todas as barragens do tipo "alteamento a montante", como as que romperam em Brumadinho e Mariana. De maneira geral, a resolução determina a desativação de todas as barragens a montante até 2021. E proibe definitivamente a construção de barragens de mineração nesse método.
} 
uma primeira vida do acontecimento, na esfera existencial, e uma segunda vida, que é quando o acontecimento aparece como narrativa, como "um objeto simbólico" (FRANÇA, 2012, p. 14).

O elemento temporal aparece como uma questão instigante por conta de sua duração. Seria possivel estipular um tempo definido para a ocorrência dos acontecimentos? Ainda na perspectiva de Queré (2012), é preciso "pensar o argumento sob as categorias de transição, do vir a ser e da emergência, em vez da substância e da simples ocorrência" (2012, p. 21). Essa visada nos alerta para a complexidade das temporalidades e, mais ainda, para a noção da indeterminação do acontecimento visto que é o presente quem movimenta o ocorrido. Os conflitos são recorrentes, como afirma Michael Pollak ao refletir sobre o trabalho de enquadramento da memória: "esse trabalho reinterpreta incessantemente o passado em função dos combates do presente e do futuro" (1989, p. 10).

No caso em questão, nota-se que o desastre da Samarco ainda não foi resolvido, tanto que a partir desse outro, ocorrido em 2019, ressurgem as tensões, contradições e 2015 é acionado de maneira recorrente. Essa recorrência expõe a questão da intriga na construção narrativa. Paul Ricoeur (2010), a partir da Poética de Aristóteles, argumenta que a composição da intriga irá configurar a narrativa, assumindo um papel mediador nesse processo.

De maneira sumária, visto que essa não é a questão central nesse trabalho, é preciso registrar que a mediação entre tempo e narrativa, para Paul Ricoeur (2010), ocorre a partir da relação entre a mímesis 1, aquilo que já está sustentado simbolicamente no mundo em ação, a mimesis 2. que é a dimensão configurante da narrativa, e ainda a mímesis 3, que "marca a intersecção entre o mundo do texto e o mundo do ouvinte ou do leitor", (RICOEUR, 2010, p. 122) trazendo a noção de refiguração da narrativa. A relação entre os três modos miméticos constitui a mediação entre tempo e narrativa. Dito de maneira precisa: "o tempo torna-se humano na medida em que está articulado de modo narrativo, e a narrativa alcança sua significação plenária quando se torna uma condição da existência temporal" (RICOEUR, 2010, p. 93, grifo do ator).

Ao refletir sobre o papel da recordação a partir de eventos traumáticos, Paul Ricoeur (2005) indica que somente o "uso crítico da memória" pode realizar a tarefa da lembrança. E é por intermédio da narrativa que "a memória é levada à linguagem" (RICOEUR, 2005, p. 4) e assume esse compromisso. "É, pois, ao nivel da narrativa que se exerce primeiro o trabalho de lembrança. E a crítica ainda agora evocada parece-me consistir no cuidado em contar a outrem as histórias do passado" (p. 4). Valendo-se também das duas categorias utilizadas por Koselleck, ele diz que embora alguns acontecimentos do passado não sejam passíveis de alterações, visto que já ocorreram, eles "permanecem abertos a novas interpretações", em função das lembranças que são acionadas pelo presente. Ainda que nesse texto em específico, Ricoeur esteja refletindo sobre o caráter político do perdão (a partir de Freud), ele afirma que o que vale para a memória pessoal serve também para a memória partilhada e para a história escrita pelos historiadores. E, seria possivel acrescentar, pode valer também para a narrativa jornalistica.

E essa perspectiva é relevante, visto que há outras possibilidades de se acionar a memória, conforme discute Aleida Assmann (2011), ao apresentar dois conceitos: a "memória Ars" e a "memória Vis". O primeiro, a "memória arte", compreende a memória enquanto técnica, compreendendo o sentido antigo da palavra arte, que envolve práticas de armazenamento humanas ou de dispositivos, aproximando-se da noção de registro. A segunda, a "memória potência", considera a memória como dotada de uma dinâmica própria, ou seja, uma espécie de energia sujeita à ação do tempo e, por isso, envolve dinâmicas mais complexas acionadas pelo presente. Considera-se que essa segunda visada seja a mais próxima da acepção adotada por esse trabalho.

De que maneira, portanto, essas narrativas tensionam o real produzindo sentidos e expondo sujeitos, ocorrências e modos de apreensão do 
social, tendo como mote a questão da memória é o que se discute nesse artigo. Levando em consideração ainda que essas narrativas são contraditórias e conflituosas, como argumenta Fernando Resende: "O mundo contado nos jornais, à luz da narrativa, é menos da ordem da retórica das imparcialidades e objetividades, do que do jogo de forças, das negociações e dos embates próprios do mundo da vida (RESENDE, 2011, p. 134).

O jornalismo é tido aqui como um dispositivo capaz de evocar uma memória de um passado inconcluso e ainda como potência no sentido de acionamento de um futuro, ou seja, de possiveis. Jeffrey Olick (2014) argumenta que os objetos dos estudos da memória passam, necessariamente, pelo campo jornalístico, independentemente de seu reconhecimento público: "nossa memória dos acontecimentos passados comumente incorporam as imagens jornalísticas que o próprio jornalismo enquadrou. As memórias dos eventos públicos são, então, indivisiveis de suas coberturas jornalisticas"7 (OLICK, p. 28, tradução nossa).

No caso em análise, por conta da extensiva reverberação do acontecimento e pelo componente de registro que hoje é viabilizado pelos processos de arquivamento digital (e, consequentemente, da disponibilidade de acesso), é possivel colocar o jornalismo na esfera de composição da memória coletiva conferindo a ele o papel de "testemunho midiático" dos acontecimentos e histórias de vida das pessoas envolvidas (READING, 2014), conforme se verá no próximo tópico.

\section{Narrativas sobre Brumadinho/Vale associadas à Mariana/Samarco e o papel testemunhal do jornalismo}

Se o jornalismo configura narrativas e se é por intermédio delas que atribuímos sentido ao tempo, o jornalismo diz não apenas de seu momento, mas também das possibilidades que o seu tempo permite atribuir ao passado e até mesmo ao futuro. Nas palavras de Queré, "o passado se modifica porque o presente passa por mudanças: um presente diferente faz surgir um passado diferente" (2012, p. 27).

Diante desse ponto de vista, e das questões levantadas no item anterior, será acionado o método de Análise de Conteúdo das matérias, ancorado nos conceitos de acontecimento e memória, em associação com o papel testemunhal do jornalismo. Importante registrar que embora a análise de conteúdo apresente algumas limitações, ela pode trazer questões inauditas para o processo de investigação. Nessa visada, serão utilizados os "operadores de memória" propostos por Neiger, Zandberg e Meyers (2014). Os autores, ao investigarem as histórias relacionadas ao Holocausto e às suas vitimas, argumentam que as narrativas da memória coletiva não estão descoladas das temporalidades. O presente acaba tendo condições estruturais e culturais para avaliação e compreensão sobre o passado.

Eles argumentam que as reportagens associadas à memória coletiva acionam os chamados "portadores da memória" que garantem a conversão de eventos do passado em notícias atuais. Nessa pesquisa, eles conseguiram então identificar quatro principais condutores:

1. "Sujeitos" - pessoas ou grupos relacionados aos acontecimentos, que servem para comprovar determinada ocorrência;

2. "Lugares" - locais igualmente associados aos acontecimentos, onde os eventos aconteceram ou são rememorados;

3. "Objetos" - meios materiais que confirmam ou simbolizam os acontecimentos

4. "Fenômenos" - práticas e/ou atitudes comportamentais associadas ao ocorrido e que estão no centro dos acontecimentos noticiados.

Traduzindo de maneira específica para esse estudo, optou-se por utilizar dois operadores no sentido de compreender de que maneira as fontes são acionadas para tratar do assunto. Serão identificados os portadores "Fenômeno"

\footnotetext{
7 Do original: our memory of such events often incorporates the journalistic images of the events that journalism itself framed. Memory of public events is thus ultimately inseparable from their journalistic coverage.
} 
e "Sujeitos", visto que os "Lugares" já estão definidos a priori (Mariana e Brumadinho) e os "Objetos" também estão associados às próprias barragens. Esses portadores serão identificados a partir de sua presença hegemônica, já que em muitas matérias há um entrecruzamento deles. A categoria "Fenômeno" será reconhecida, em especial, a partir de fontes relacionadas aos poderes judiciário e executivo, enquanto o portador "Sujeitos" será identificado quando a referência aos atingidos for hegemônica na matéria. A partir então desses "portadores de memória", será possivel acompanhar a cobertura das matérias encontradas e compreender as relações entre os usos da memória e a composição dos discursos jornalisticos sobre os rompimentos das duas barragens em Minas Gerais, bem como o papel testemunhal do jornalismo.

Para a definição do corpus, foi utilizado um banco de dados de notícias, mantido por um servidor full time do jornalista Marcelo Soares (que gentilmente cedeu informações para esta pesquisa), a partir de coleta de links das principais publicações do Brasil, com as seguintes palavraschave: Brumadinho, barragem/barragens, Vale, de/em Mariana, Samarco, rejeitos, lama, BHP, Fundação Renova. Optou-se então por trabalhar com os principais jornais da chamada imprensa de referência; no caso, os jornais Folha de S. Paulo, $O$ Estado de S. Paulo (Estadão) e O Globo. O periodo de coleta abarcou os dias 25 de janeiro (dia do rompimento da Barragem da Vale) até o dia 7 de fevereiro de 2019, perfazendo um total de 14 dias de cobertura. O resultado apontou a veiculação de 764 matérias (entre notas, artigos, reportagens e notícias - algumas repetidas em editorias diferentes). A partir desse levantamento, foram separados os textos que estabeleciam algum tipo de conexão entre Mariana e Brumadinho, o que gerou 48 chamadas (quase $7 \%$ ) que seguem listadas na Tabela 1, a seguir, que contempla a manchete, a data, o veículo e o "portador de memória" preponderante.

TABELA 1 - Chamadas dos jornais com conexão entre Mariana e Brumadinho

\begin{tabular}{llll}
\hline CHAMADA Dos JORNAIS & DATA & JORNAL & PoRTADoRES \\
\hline Imprensa internacional destaca tragédia em Brumadinho e [...] & $25 / 01$ & Folha & Fenômeno \\
Presidente da Vale compara rompimento ao de Mariana [...] & $25 / 01$ & Folha & Sujeito \\
Brasil não avançou em fiscalização de barragens [...] & $25 / 01$ & Folha & Fenômeno \\
Rompimento de barragem em Brumadinho acontece três anos [...] & $25 / 01$ & O Globo & Fenômeno \\
Raquel Dodge diz que tragédia em Brumadinho [...] & $25 / 01$ & O Globo & Fenômeno \\
Parece que nunca aprendemos', diz pesquisador [...] & $25 / 01$ & O Globo & Fenômeno \\
Comitê de crise avalia que desastre em Brumadinho [...] & $25 / 01$ & Estadão & Fenômeno \\
Após Mariana, especialistas pressionavam por lei [...] & $25 / 01$ & Estadão & Fenômeno \\
Somos vítimas de uma classe política que ignora a Justiça' [..] & $25 / 01$ & Estadão & Fenômeno \\
'Dano humano' em Brumadinho será maior que Mariana [...] & $25 / 01$ & Estadão & Fenômeno \\
'Certamente há um culpado', diz Dodge sobre barragem [...] & $26 / 01$ & Folha & Fenômeno \\
*Funcionário da Vale morto em Brumadinho ia tirar férias [...] & $27 / 01$ & O Globo & Sujeito \\
Segunda tem l...] peça com relatos da tragédia de Mariana (MG) & $28 / 01$ & Folha & Fenômeno \\
De Mariana a Brumadinho: rio de descaso e insegurança & $28 / 01$ & Folha & Fenômeno \\
Viúva de vítima de Mariana e irmã ajudam atingidos [...] & $28 / 01$ & Folha & Sujeito \\
Não esperem nada da Vale', diz promotor a atingidos após [...] & $28 / 01$ & Folha & Sujeito
\end{tabular}




\section{CHAMADA DOS JORNAIS}

* Na Câmara, frente ambientalista vai propor proibição [...]

Nada foi feito para prevenir, diz promotor [...]

Estes fatos não são acidentes e a pena é 'tranca', diz promotor [...]

Tragédia em Mariana ainda não tem culpados,e Samarco não [...]

Vale se compromete a acabar com barragens como as [...]

Mariana, Brumadinho e...

Samarco deve R\$350 milhões ao Ibama por rompimento [...]

Samarco não pagou nenhuma multa ao Ibama referente [...]

Brumadinho: impacto na indústria pode se prolongar, como [...]

Vale vai paralisar barragens do tipo de Brumadinho e Mariana

Especialistas elogiam decisão da Vale de parar produção [...]

Tragédia de Brumadinho pode reascender ação[...]sobre Mariana

Obsoleta, técnica de construção de barragem era a mesma [...]

Mesmo após tragédia em Mariana, projetos buscam afrouxar [...]

Sobreviventes de Mariana revivem tragédia e relatam raiva [...]

Vale põe réu do caso Mariana para negociar [...] Brumadinho

Folha de S. Paulo [...] tragédias de Mariana e Brumadinho

"Minas Gerais tem 50 barragens [...] no mesmo modelo[...]

Brumadinho também é Mariana

Mineradoras foram alertadas em 2014 sobre 'perda [...]

Toffoli e Raquel Dodge criam observatório para vítimas [...]

Sobrevivente de rompimento em Mariana morreu em Brumadinho

Governo deve determinar eliminação todas barragens [...]

Em Mariana, memória do desastre e a espera por um novo lar

Balanço da Vale sofreu poucas mudanças após tragédia [...]

Causa do rompimento da barragem de Brumadinho pode ser [...]

Depois da tragédia de Mariana, licenciamento ambiental [...]

A tragédia de Mariana e a farsa de Brumadinho

Em dois anos, ação contra executivos e mineradoras [...]

Bombeiro que escapou de Mariana morreu no desastre de [...]

Ex-presidente da Samarco quis saber 'quem entrou na PF' [...]

Há 3 anos, rompimento de barragem de Mariana causou [...]

\section{DATA}

JORNAL

$28 / 01$

$28 / 01$

28/01

29/01

29/01

29/01

29/01

29/01

29/01

29/01

29/01

29/01

29/01

29/01

30/01

30/01

31/01

31/01

31/01

31/01

31/01

1\% $/ 02$

1\%/02

1\%/02

1\%/02

02/02

02/02

02/02

03/02

03/02

05/02

07/02

Estadão

Estadão

Folha

Folha

O Globo

O Globo

Folha

Folha

\section{O Globo}

o Globo

O Globo

O Globo

O Globo

Fenômeno

Estadão

Fenômeno

Estadão

Fenômeno

Fenômeno

Estadão

Fenômeno

O Globo

Sujeito

Fenômeno

O Globo

Fenômeno

Estadão

Fenômeno

Fenômeno

Estadão Fenômeno

Estadão Fenômeno

O Globo Sujeito

Fonte: Elaborada pela autora

*Matéria duplicada, com algumas alterações, e que foi publicada em outra editoria do próprio veículo 
Imagem 1 - Gráficos com os portadores de memória

Folha

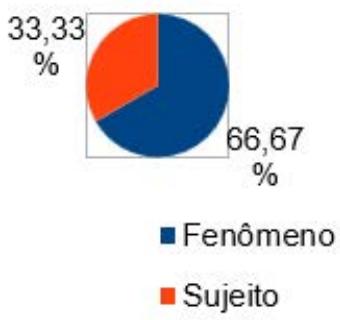

Estadão

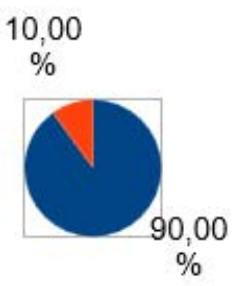

- Fenômeno

- Sujeito

\section{O Globo}

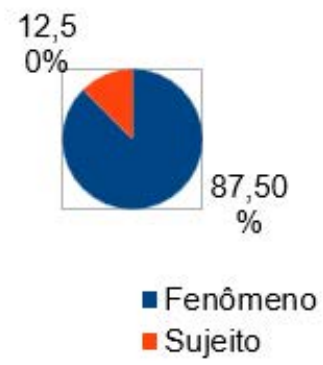

Fonte: Elaborado pela autora

As matérias, como é possivel perceber pelas manchetes, encetam novas abordagens sobre o real, configurando outros modos de narrar na medida em que a maioria delas explicita certo consenso de reprovação sobre o ocorrido. A ausência de termos como "acidente" ou "catástrofe" é perceptivel no acompanhamento da maioria das matérias publicadas. Nesse sentido, verifica-se certa clivagem no discurso oficial, que, inclusive, nesse caso, é feito especialmente pela empresa, visto que o Ministério Público e os governos estadual e federal condenaram o ocorrido, já que houve uma grande reverberação do acontecimento.

Em se tratando de um acontecimento hermenêutico, o "portador" de memória denominado "Fenômeno" aparece em primeiro lugar, seguido do "Sujeito". A prevalência do critério "Fenômeno" entre as matérias da Tabela 1, com 40 ocorrências, mostra que os "sujeitos" atingidos, com 8 ocorrências, ainda não são o foco principal das coberturas de situações de conflito. A situação inesperada que o ocorrido traz implica nas tentativas de explicação do fenômeno em variadas perspectivas e, o que interessa especialmente nessa análise, com uma forte ligação com o acontecimento anterior. Essa aproximação acontece por meio de aspectosjuridicos, ambientais, sociais, culturais, políticos e econômicos.

Embora o segundo "portador" de memória apontado na Tabela 1 seja o "Sujeito" atingido, ele ainda tem pouco espaço na cobertura que relaciona os dois acontecimentos. Os gráficos da Imagem 1 atestam que o "Fenômeno" é o portador prioritário de condução da narrativa sobre o ocorrido, com forte presença de fontes institucionais, ligadas aos poderes judiciário e executivo. Das 48 matérias elencadas, somente 8 contemplaram os sujeitos atingidos. Nota-se então que os portadores de memória privilegiados foram as vozes do poder judiciário, visto que o acontecimento de 2015 ainda está em aberto e enfrenta processos judiciais e situações de alerta em várias regiões do país.

Outro resultado encontrado e que merece ser registrado refere-se a questão semântica das manchetes. Ao menos nas matérias listadas na Tabela 1, percebe-se que a palavra "acidente" só aparece uma única vez e na cobertura do jornal $O$ Globo, nos outros dois jornais é forte a presença da palavra "tragédia", que, de certa forma, pode ser considerada genérica, mas justamente pela amplitude não naturaliza o acontecimento como a noção de "acidente" poderia fazê-lo.

Nota-se que a impunidade às empresas mineradoras responsáveis pelo rompimento da barragem em Mariana representa o principal conteúdo das matérias que voltam ao passado para falar sobre o presente. "'Não esperem nada da Vale', diz promotor a atingidos após experiência de Mariana" (LINHARES, 2019) é uma reportagem que narra a primeira reunião entre os atingidos, o Ministério Público, a Ordem dos Advogados do Brasil e o Movimento dos Atingidos por Barragens e a Vale. A matéria recupera, em várias partes, o acontecimento de Mariana no sentido de se evitar a repetição dos mesmos erros do passado, como a declaração do promotor que incita os atingidos: "Vocês que vão 
conseguir, unidos, resolver os problemas de vocês", além do depoimento do defensor público de Minas Gerais que relembra Mariana em várias passagens, explicitando ainda que a empresa tenta dividir a comunidade proporcionando auxilio emergencial para alguns e não para outros. ${ }^{8}$

Outra matéria que também tem como "portador de memória" o "Fenômeno" é "Estes fatos não são acidentes e a pena é 'tranca', diz promotor de Mariana" (MORAES, 2019). Ela expõe a crueza dos fatos ao qualificar o acontecimento como um evento muito grave, de acordo com o promotor responsável pela assistência às vitimas da Samarco. Para ele, este tipo de barragem deveria ter sido proibido após 2015, reforçando que não houve nenhuma ação preventiva depois do rompimento da barragem em 2015. "Esses fatos não são acidentes, são crimes. São homicídios, lesões corporais, crime ambiental. E a pena é de prisão, é 'tranca' como se diz no jargão popular". Nota-se uma leitura bem radical do social.

No dia seguinte ao rompimento da barragem, a Procuradora Geral da República, Raquel Dodge, na matéria veiculada pela Folha, intitulada 'Certamente há um culpado', diz Dodge sobre barragem da Vale em Brumadinho" (LINHARES, 2019) diz que o Ministério Público terá uma ação "mais rígida, mais severa e mais firme" após os aprendizados de Mariana. Em outra matéria, "Toffoli e Raquel Dodge criam observatório para vítimas de Brumadinho, Mariana e Boate Kiss" (MOURA; CURY, 2019), veiculada pelo Estadão, ela e o presidente do Supremo Tribunal Federal (STF), ministro Dias Toffoli, indicam que a justiça brasileira não está preparada para atuar em situações conflitantes como as citadas. A fala do presidente do STF é autoexplicativa: "Aquilo que aconteceu em Mariana, na Boate Kiss, ainda não demos enquanto sistema de Justiça a devida resposta. Que isso não se repita em Brumadinho [...] e que possamos enfrentar essas questões de uma vez por todas".

O lastro com o rompimento de 2015 também aparece na matéria do dia 29 de janeiro, do jornal O Globo: "Samarco não pagou nenhuma multa ao Ibama referente à tragédia em Mariana" (COUTINHO, 2019). Fica evidente a angulação de impunidade do desastre anterior, já que a mineradora, de acordo com o lbama, recorreu de todas as multas. "Apesar de os autos terem sido confirmados, a Samarco insiste em recorrer das decisões administrativas, buscando afastar sua responsabilidade pelo desastre", informa o órgão em nota enviada aos meios.

"Em Mariana, memória do desastre e a espera por um novo lar" (PEREIRA, 2019), matéria publicada pelo Estadão no dia $1^{\circ}$ de fevereiro, o jornalista Pablo Pereira volta ao local do crime ambiental e entrevista algumas pessoas que ainda continuam na expectativa de um local definitivo de moradia. Essa e as outras que trazem como "portadores" a classificação de "Sujeito" orientam uma cobertura que busca identificar de maneira particular algumas das pessoas que sofreram/sofrem com o acontecimento traumático. Elas seguem como testemunhas e, de alguma forma como exemplos vivos dos transtornos causados pela mineradora; até porque a situação problemática ainda não foi solucionada. Um sentimento de impunidade parece surgir do movimento de leitura desse material, como o depoimento dado por um atingido da Samarco que, à época da produção da matéria "Sobreviventes de Mariana revivem tragédia e relatam raiva e medo após Brumadinho" (BARBON; CARAZZAI, 2019), estava se organizando com os demais para ajudar os atingidos da Vale: "A única coisa a dizer para eles é que somos solidários, que podemos dividir essa luta. A Vale usa o tempo como um aliado para que tudo caia no esquecimento".

De todo modo, percebe-se que a cobertura traz elementos indicadores da ausência de prevenção, de organização e até mesmo falta de responsabilidade da empresa e do poder público. Se os sujeitos, pensados aqui como testemunhas do acontecimento, não aparecem em demasia, pode-se argumentar, entretanto que o jornalista, também pode ser pensado como testemunha

8 Essa experiência levou a um acordo entre a Vale, representantes dos atingidos por barragens e a Justiça que fecharam um acordo para o pagamento de mil reais por adulto, e 300 reais por adolescente ou criança de Brumadinho durante um ano. O Termo de Acordo Preliminar (TAP) também contempla quem mora em uma faixa de aproximadamente 1 quilômetro do Rio Paraopeba, entre Brumadinho e a Hidrelétrica Retiro Baixo. 
que acompanha o desenrolar dos fatos próximo ao local da ocorrência.

Para Jeanne Marie Gagnebin (2006) testemunha é também "aquele que não vai embora, que consegue ouvir a narração insuportável do outro e que aceita que suas palavras levem adiante, como num revezamento, a história do outro" (GAGNEBIN, 2006, p. 57). Seguindo esse raciocínio, acompanhado da pergunta feita por Ana Cláudia Peres: "Até que ponto o jornalismo é, também, testemunho?" (PERES, 2016, p. 94), é pertinente dizer que a maioria das matérias que tem o "sujeito" como mote contém a assinatura de um jornalista, o que exprime, em certa medida, a presença desse mediador na intersecção desses dois acontecimentos. A experiência sensorial, física, desse profissional também orienta a cobertura, visto que é um sujeito falando sobre sujeitos.

Em post no blog de sua autoria, de 25 de fevereiro de 2019, o jornalista Pablo Pereira comenta sobre sua presença no local do desastre: "Vida que segue, dirão... Não. Não depois de tanto sofrimento, tanta lama cobrindo as pessoas e arrasando tudo! Foi no 26 de janeiro, um dia depois [...] que encontrei a pequena cidade mineira" (PEREIRA, 2019). Ele segue com seu depoimento, comentando sobre a correria de centenas de pessoas aflitas em busca de informações, presenciando "velórios sem corpo presente, doloridos funerais arranjados às pressas, perplexidade, mais um monte de gente desaparecida, a extrema crueldade com as familias".

Não há uma diferença significativa dos três jornais em relação à cobertura do acontecimento. As fontes são semelhantes, muito provavelmente por conta da proximidade da ocorrência. O que se verifica, entretanto é que o jornal O Estado de S. Paulo é o que faz uma cobertura mais extensa, relacionando os dois acontecimentos de maneira mais direta. Enquanto a Folha publicou 12 matérias, O Globo veiculou 16 e O Estado de S. Paulo publicou 20. Verifica-se também que as matérias têm alto teor crítico, justamente pela relação entre os dois acontecimentos. Vale recorrer ao questionamento de Neiger, Zandberg e Meyers (2014) sobre a resolução de problemas do passado: "Pode a sociedade tomar eventos do passado como encerrados, encapsulados na História, enquanto notícias relacionadas a suas implicações continuam sendo transmitidas?"9 (NEIGER; ZANDBERG; MEYERS, 2014, p. 125. tradução nossa). Percebe-se a tentativa da cobertura em enquadrar os acontecimentos como decorrências de uma narrativa ainda em curso.

\section{Considerações finais}

Vale ressaltar que não se deve desconsiderar todos os agentes envolvidos na rotina jornalística, como as empresas, os editores, os jornalistas e o próprio público, mas é possivel afirmar que um acontecimento inconcluso como o de Mariana abre brechas para o advento de uma cobertura mais ampla do que o costumeiro em outras editorias como política ou economia, por exemplo.

A análise de conteúdo das matérias coletadas, em geral, revela o uso crítico da memória; mesmo que as pessoas atingidas em Brumadinho ainda não tenham conseguido se expressar plenamente, a apuração dos jornalistas acionou depoimentos daqueles que já passaram por situação semelhante (no caso, em Mariana) para configurar narrativas do ocorrido, como reflete Beatriz Sarlo ao dizer que "não há testemunho sem experiência, mas tampouco há experiência sem narração [...] A narração também funda uma temporalidade que a cada repetição e a cada variante torna a se atualizar" (SARLO, 2007, p. 24). Assim, os sentidos puderam ser construidos por intermédio de uma análise crítica do presente pelas conexões estabelecidas entre os dois acontecimentos, bem como pelos testemunhos dos próprios jornalistas, já que a maioria das matérias está assinada, e traz indícios da necessidade de justiça e reparação da impunidade.

Estudos sobre a memória da ditadura, realizados por Marta R. Maia e Thales Vilela Lelo (2015), revelam que o jornalismo está intrinsecamente conectado ao link experiência-memória-política, e o seu papel, portanto, na configuração de realidades possiveis por intermédio da cobertura

9 Do original: Can Society address its past events as bygones, encapsulated in history, while live News regarding its implications keeps streaming in? 
do acontecimento não pode ser desprezada. Os três jornais estabeleceram conexões entre os dois acontecimentos, revelando uma disputa de sentidos a partir da ausência de reparação e de justiça para os atingidos de Mariana. Não se está advogando aqui que a cobertura foi profundamente crítica. Como já falado na introdução dessas "Considerações finais", há outras questões envolvidas no processo jornalístico, inclusive o aspecto do financiamento dos veículos, mas nota-se uma relativa contextualização nessa cobertura, muito provavelmente influenciada pelos danos causados às pessoas e ao meio-ambiente e pela falta de punição aos responsáveis.

É sabido que a mineração é responsável por $5 \%$ do PIB brasileiro e que forças políticas e econômicas estão na disputa de sentidos sobre a situação complexa que o país atravessa em relação às barragens e à mineração, entretanto, como se pôde verificar nas matérias coletadas, os desdobramentos de acontecimentos desse tipo são comprometedores para o próprio desenvolvimento do país.

Os veículos, ao realizarem uma cobertura estendida, conseguiram ser "portadores de memória" de um evento conflituoso, e que ainda está em processo, sem recorrer à espetacularização do acontecimento. A presença dos portadores "Fenômeno" e "Sujeito" aparece como indicativo dos modos de apreensão do real por parte dos repórteres, que buscaram, ao menos nas matérias da Tabela 1, configurar narrativamente os sujeitos e os acontecimentos a partir do lastro mnemônico. Nesse sentido, o "espaço de experiência" pôde ser expresso pela presença dos sujeitos envolvidos, considerando também o repórter como parte desse processo testemunhal de configuração do real. 0 "horizonte de expectativas" ainda está em aberto visto que o rompimento é recente e muitos outros campos problemáticos podem ser acionados a partir da situação atual. O acontecimento inconcluso de Mariana ainda reverbera na sociedade. Quando outro acontecimento de mesma ordem "acontece" provoca uma afetação ainda mais ampla, tanto pelo número de pessoas que atinge diretamente (no caso,
15 vezes mais), quanto pelo crime não resolvido.

Muitas vezes confinado somente como o espaço do presente, o fazer jornalístico, entretanto, pode ser pensado como o lugar do entrecruzamento das temporalidades, já que o tempo presente não se faz sem as marcas do passado e as perspectivas do futuro. Percebese como a cobertura sobre o acontecimento de 2019 manteve pontes com o de 2015 e, mais ainda, contribuiu para a construção de uma memória coletiva sobre um passado recente ao reatualizar as histórias daqueles que sofreram as consequências do descaso para com a situação de moradores em regiões próximas às barragens. É possivel ainda dizer que o jornalismo pode. muitas vezes, transbordar o factual, ao abordar fenômenos e sujeitos a partir de acontecimentos que podem potencializar ações futuras.

\section{Referências}

ASSMANN, Aleida. Espaços da recordação: formas de transformação da memória cultural. Campinas: Editora Unicamp, 2011.

BARBON, Júlia; CARAZZAI, Estelita H. Sobreviventes de Mariana revivem tragédia e relatam raiva e medo após Brumadinho. Folha de S. Paulo, São Paulo, 30 jan. 2019. Disponivel em: https://WwW1.folha.uol.com. br/cotidiano/2019/01/sobreviventes-de-mariana-revivem-tragedia-e-relatam-raiva-e-medo-apos-brumadinho.shtml. Acesso em: 10 fev. 2019

BARROS, José D'Assunção. O tempo dos historiadores Petrópolis, RJ: Vozes, 2013.

BRAGA, José Luiz. Dispositivos interacionais. In: ENCONTRO DA COMPÓS, 20., jun. 2011, Porto Alegre. Anais [...]. Porto Alegre: [s. n.], 2011.

COUTINHO, Mateus. Samarco não pagou nenhuma multa ao Ibama referente à tragédia em Mariana. $\mathbf{O}$ Globo, Rio de Janeiro, 29 jan. 2019. Disponivel em: https://oglobo.globo.com/brasil/samarco-nao-pagou-nenhuma-multa-ao-ibama-referente-tragedia-em-mariana-23410255. Acesso em: 06 jan. 2019.

FRANÇA, Vera V. O acontecimento para além do acontecimento: uma ferramenta heuristica. Acontecimento: reverberações. Belo Horizonte: Autêntica, 2012. p. 39-51.

FRANÇA, Vera V. O acontecimento e a mídia. Revista Galáxia, São Paulo, n. 24, p. 10-21, dez. 2012. Disponivel em: http://revistas.pucsp.br/index.php/galaxia/article/ view/12939/9406. Acesso em: 5 dez 2018.

GAGNEBIN, Jeanne M. Lembrar, escrever, esquecer. São Paulo: Editora 34, 2006. 
KOSELLECK, Reinhart. Futuro Passado: Contribuição à semântica dos tempos históricos. Rio de Janeiro: Contraponto, Editora Puc-RJ, 2006.

LINHARES, Carolina. "Certamente há um culpado", diz Dodge sobre barragem da Vale em Brumadinho. Folha de S. Paulo, São Paulo, 26 jan. 2019. Disponivel em: https:// www1.folha.uol.com.br/cotidiano/2019/01/certamente-ha-um-culpado-diz-dodge-sobre-barragem-da-vale-em-brumadinho.shtml. Acesso em: 05 fev. 2019.

LINHARES, Carolina. "Não esperem nada da Vale" diz promotor a atingidos após experiência de Mariana. Folha de S. Paulo, São Paulo, 28 jan. 2019. Disponivel em: https:// www1.folha.uol.com.br/cotidiano/2019/01/nao-esperem-nada-da-vale-diz-promotor-a-atingidos-apos-experiencia-de-mariana.shtml. Acesso em: 05 fev. 2019.

MAIA, Marta R.; LELO, Thales V. O potencial crítico das narrativas jornalisticas sobre o periodo ditatorial no Brasil. Brazilian Journalism Research (Online), v. 11, p. 128-145, 2015. Disponivel em: https://bjr.sbpjor.org.br/ bjr/article/view/677. Acesso em: 20 jan. 2019. https:// doi.org/10.25200/BJR.v11n1.2015.677.

MORAES, Igor. Estes fatos não são acidentes e a pena é 'tranca', diz promotor de Mariana. Folha de S. Paulo, São Paulo, 28 jan. 2019. Disponivel em: https://politica. estadao.com.br/blogs/fausto-macedo/estes-fatos-nao-sao-acidentes-e-a-pena-e-tranca-diz-promotor-de-mariana/. Acesso em: 05 fev. 2019.

MOURA, Rafael M.; CURY, Teo. Toffoli e Raquel Dodge criam observatório para vítimas de Brumadinho, Mariana e Boate Kiss. Estado de S. Paulo, São Paulo, 31 jan. 2019. Disponivel em: https://brasil.estadao.com.br/ noticias/geral,toffoli-e-raquel-dodge-criam-observatorio-para-vitimas-de-brumadinho-mariana-e-boate-kiss,70002702586. Acesso em: 03 fev. 2019.

NEIGER, Motti; ZANDBERG, Eyal; MEYERS, Oren. Reversed memory: Commemorating the past through coverage of the present. In: ZELIZER, Barbie; TENENBOIM-WEINBLATT, Keren (ed.). Journalism and Memory. New York: Palgrave Macmillan UK, 2014. p. 113-127. https:// doi.org/10.1057/9781137263940_8.

NORA, Pierre. Entre história e memória: a problemática dos lugares. Revista Projeto História, São Paulo, v. 10, p. 07-28, 1993.

OLICK, Jeffrey K. Reflections on the underdeveloped relations between journalism and memory studies. In: ZELIZER, Barbie; TENENBOIM-WEINBLATT, Keren (ed.). Journalism and Memory. New York: Palgrave Macmillan UK, 2014. p. 17-31. https://doi. org/10.1057/9781137263940_2.

PEREIRA, Pablo. Em Mariana, memória do desastre e a espera por um novo lar. O Estado de S. Paulo, São Paulo, 1 fev. 2019. Disponivel em: https://brasil.estadao. com.br/noticias/geral,em-mariana-memoria-do-desastre-e-a-espera-por-um-novo-lar.70002702959. Acesso em: 10 fev. 2019.

PEREIRA, Pablo. Vida que segue? Não para as vítimas de Brumadinho. Blog da Garoa. [S. l.: s. n.]: [201?]. Disponivel em: https://sao-paulo.estadao.com.br/blogs/ blog-da-garoa/vida-que-segue-nao-para-as-vitimas-de-brumadinho/. Acesso em: 03 mar. 2019.
PERES, Ana C. Narrar o outro: notas sobre a centralidade do testemunho para as narrativas jornalísticas. Revista Galáxia, São Paulo, n. 31, p. 92-104, abr. 2016. Disponivel em: https://revistas.pucsp.br/galaxia/article/ view/20913/19080. Acesso em: $11 \mathrm{dez} .2018$ https:// doi.org/10.1590/1982-25542016120913.

POLLAK, Michael. Memória, esquecimento e silêncio Estudos Históricos, Rio de Janeiro, v. 2, n. 3. p. 3-15, 1989.

QUERÉ, Louis. A dupla vida do acontecimento: por um realismo pragmatista. In: FRANÇA, Vera Regina Veiga; OLIVEIRA, Luciana de (org.). Acontecimento: reverberações. Belo Horizonte: Autêntica Editora, 2012. p. 21-38.

READING, Anna. The journalist as memory assembler: non-memory, the war on terror and the shooting of Osama Bin Laden. In: ZELIZER, Barbie; TENENBOIM-WEINBLATT, Keren (ed.). Journalism and Memory. New York: Palgrave Macmillan UK, 2014. p. 164-178. https://doi.org/10.1057/9781137263940_11.

RESENDE, Fernando. Às desordens e aos sentidos: a narrativa como problema de pesquisa. Jornalismo contemporâneo: figurações, impasses e perspectivas. Salvador/EDUFBA, Brasília/Compós, 2011. p. 120-134.

RICOEUR, Paul. Tempo e Narrativa: A intriga e a narrativa histórica. V. 1. São Paulo: Editora WMF Martins Fontes, 2010.

RICOEUR, Paul. O perdão pode curar? Tradução: José Rosa. Revista Viragem, [s. l.], n. 21, 1996. Disponivel em: http://www.lusosofia.net/textos/paul_ricoeur_o_perdao_pode_curar.pdf. Acesso em: 14 de nov. 2019.

SARLO, Beatriz. Tempo passado: Cultura da memória e guinada subjetiva. São Paulo: Cia das Letras, 2007.

Top Sites in Brazil. Disponivel em: https://www.alexa. com/topsites/countries/BR. Acesso em 22 jan. 2019

\section{Marta Regina Maia}

Doutora em Comunicação pela Universidade de São Paulo (USP, São Paulo, SP, Brasil) e pós-doutora em Comunicação pela Universidade Federal de Minas Gerais (UFMG, Belo Horizonte, MG, Brasil). Professora permanente do Programa de Pós-graduação em Comunicação pela Universidade Federal de Ouro Preto (UFOP), Mariana, MG, Brasil. Lider do Grupo de Pesquisa "Ponto: Afetos, Gêneros, Narrativas" (CNPq/ UFOP). Uma das coordenadoras da Rede de Pesquisa Narrativas Midiáticas Contemporâneas (Renami) da SBPJor. Orientadora de Projetos de pesquisa sobre narrativas jornalisticas.

\section{Endereço para correspondência}

Marta Regina Maia

Universidade Federal de Ouro Preto

Instituto de Ciências Sociais Aplicadas

Rua do Catete, 166

Centro, 35420000

Mariana, MG, Brasil 